respiratory health and risk factors. Appropriate investigations and respiratory plans were initiated.

Results $72 / 87$ children identified by school nurses were assessed. 49 M:23 F. 47 (65\%) had cerebral palsy. 9 (13\%) patients had respiratory admissions to hospital in the previous year, $3(4 \%)$ to PICU. $44(61 \%)$ had $<2$ courses of antibiotics for respiratory infections in the last year, 15 (20\%) 2-3 courses and $13(18 \%) \geq 4$ courses. 2 children were on home oxygen, 1 on NIV and 1 had a tracheostomy. 7 (10\%) had established respiratory follow up. 21 (29\%) patients had concerns about safety of swallow and 14 of these were orally fed. $14(19 \%)$ had persistent symptoms of GORD. 27 (38\%) had clinical signs or history of upper airway obstruction and $6(8 \%)$ had abnormal oximetry. 27(\%) had scoliosis which was severe in 4 (6\%). All 9 patients with previous admissions had risk factors. 8 of 9 had multiple risk factors. 7 had swallowing concerns, 8 UAO and 1 GORD. All had $\geq=2$ courses antibiotics in the previous year. No children with $<2$ courses of antibiotics were admitted. Only 4/17 children with significant respiratory morbidity (admission and/or $\geq 4$ courses antibiotics) had a prior respiratory review.

Conclusions Although many children with severe neurological impairment did not have frequent respiratory infections or admissions, those with significant respiratory morbidity were predictable. They had multiple courses of antibiotics, admissions to hospital and significant risk factors. Many children had underlying risk factors which had not been addressed. We propose that a simple screening tool to identify children at risk and review risk factors for respiratory morbidity has the potential to improve the quality of life for this vulnerable group.

\section{P84 LONGER TERM TOLERABILITY OF NEBULISED HYPERTONIC SALINE IN CHILDREN WITH RESPIRATORY DISEASE}

GM Housley, N Sanghani, A Bush. Royal Brompton and Harefield NHS Foundation Trust, London, UK

\subsection{6/thoraxjnl-2017-210983.226}

Introduction Ultrasonically nebulised hypertonic saline (HS) is used to obtain microbiology samples from children with respiratory disease and is generally well tolerated [Pediatr Pulmonology2016;51:778-86]. Evidence for long term use is poor.

Hypothesis Despite an initial successful trial, HS would be discontinued at follow-up due to treatment burden.

Aims Report the Results of initial nebulised HS trial; determine reported HS use in the longer term.

Methods We determined prevalence of bronchoconstriction ( $\geq 15 \%$ drop in $\mathrm{FEV}_{1} \pm$ symptoms) in children who had a first dose (Drug Reaction Assessment (DRA)) of 3.5 or $7 \%$ HS from April 2011-March 2016, and one year later identified if use was ongoing, or reasons for stopping.

Results 88 DRAs were conducted in patients (45 male) age 5 months-16 years (median 8 years, 6 months). Main groups were Cystic Fibrosis (30\%); Primary Ciliary Dyskinesia (30\%), bronchiectasis (15\%), asthma (5\%); miscellaneous (22\%). Spirometry was used in $70 \%$ of tests; $\mathrm{FEV}_{1}$ was $0.611-3.891(45 \%-106 \%$ pred). 26 patients could not perform spirometry. $7 / 78$ (9\%) tests with $7 \%$ HS failed due to intolerance or $\geq 15 \%$ decrease in $\mathrm{FEV}_{1}$ despite bronchodilator; failure was unpredictable. All 3.5\% HS tests were successful. $31 \%$ of tests included a pre-test bronchodilator; $21 \%$ who passed used a post-test bronchodilator. 11/12 patients whose $\mathrm{FEV}_{1}$ was $<70 \%$ pred safely completed the trial. Of those who passed, 5 were lost to follow up. $67 \%$ reported still using HS 1 year later (see table). Reasons for stopping were not always recorded although tolerability was the commonest cited reason.

Conclusions HS testing in children with different underlying pathologies is safe even in those with pre-existing airflow obstruction. Many still used HS after a year, but strategies to improve adherence are needed.

\begin{tabular}{|c|c|c|c|c|c|}
\hline Pathology & $\begin{array}{l}\text { Still using at } \\
1 \text { year }\end{array}$ & $\begin{array}{l}\text { Stopped using } \\
\text { by } 1 \text { year }\end{array}$ & $\begin{array}{l}\text { Unknown/lost } \\
\text { to f/up }\end{array}$ & $\begin{array}{l}\text { DRA } \\
\text { failure }\end{array}$ & Total \\
\hline $\mathrm{CF}$ & 16 & 8 & 0 & 2 & 26 \\
\hline PCD & 22 & 3 & 0 & 2 & 27 \\
\hline Bronchiectasis & 8 & 2 & 2 & 1 & 13 \\
\hline Asthma & 1 & 2 & 0 & 1 & 4 \\
\hline Miscellaneous & 12 & 2 & 3 & 1 & 18 \\
\hline Total & 59 & 17 & 5 & 7 & 88 \\
\hline
\end{tabular}

\section{P85 PRESCHOOL WHEEZE: A ROLE FOR ANTIBIOTICS?}

RJ Langley, RA Lewsey, P Davies. Royal Hospital for Children, Glasgow, UK

\subsection{6/thoraxjn|-2017-210983.227}

Introduction Acute wheeze in pre-school children is a common paediatric presentation which is usually secondary to viral illness. One of the most common and challenging situations faced by the paediatrician is whether the child also requires empirical antibiotics to cover the risk of concurrent bacterial infection. Recent studies have suggested a role for antibiotics in the management of preschool wheeze in reducing duration of episodes. ${ }^{1}$ However, antibiotics can increase microbial resistance and alter the host microbiome.

Objective To evaluate the role of antibiotics in reducing duration of episodes and readmission rates for wheeze in preschool children.

Design Retrospective analysis of wheeze presentations in preschool children requiring hospital admission over a one year period. Those children receiving antibiotics were compared to those who did not. Outcome measures included length of stay, number of oxygen days and long term readmission rates. Virology and chest radiograph data was also collected.

Results 673 cases of children (aged 1-5, 64\% male) receiving inpatient management for wheeze were analysed. All patients received bronchodilators. Patients receiving antibiotics $(n=64$; 9.5\%) were found to have a significantly increased length of inpatient stay and number of oxygen days $(p=<0.0001$; figure $1 \mathrm{~A} \& \mathrm{~B})$ compared to children not receiving antibiotics $(\mathrm{n}=609 ; 90.5 \%)$. However, children in the antibiotic group were more likely to receive a chest radiograph $(77 \%$ vs $11 \%$, $\mathrm{p}<0.0001$ ); although formal radiographic appearance was often non-specific. Virus isolation did not predict wheeze readmission rates since patients with a negative sample at presentation accounting for $46 \%$ of overall readmissions. Furthermore, there was no statistical difference in wheeze readmission rates 6-12 months after initial presentation $(p=0.94)$ between the two groups (figure 1C). 

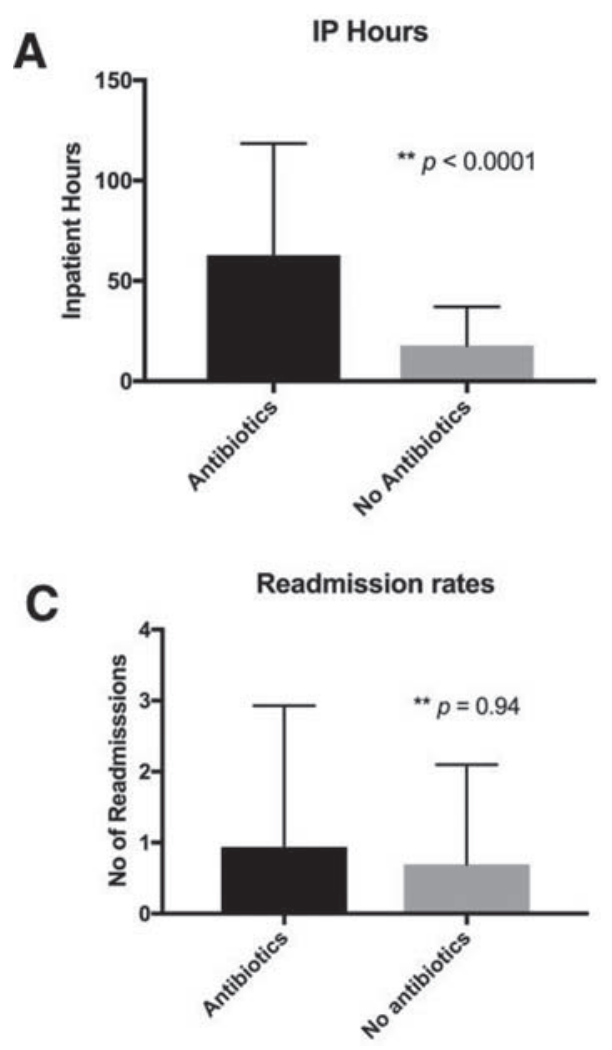

\section{Abstract P85 Figure 1}

Conclusions Early administration of antibiotics did not shorten disease course in our cohort but is correlated with prolonged inpatient stay and oxygen therapy. Furthermore, antibiotics prescribed at presentation in preschool children with wheeze do not reduce future episodes of wheeze requiring hospital admission.

\section{REFERENCE}

1. Stokholm, et al. Lancet Resp Med 2016;4:19-26.

\section{P86 IN VITRO AND CLINICAL CHARACTERISATION OF THE ANTISTATIC VALVED HOLDING CHAMBER AEROCHAMBER PLUS ${ }^{\circledR}$ FLOW-VU ${ }^{\circledR}$ FOR ADMINISTRATING TIOTROPIUM RESPIMAT ${ }^{\circledR}$ IN 1-5- YEAR-OLD CHILDREN WITH PERSISTENT ASTHMATIC SYMPTOMS}

${ }^{1} \mathrm{H}$ Wachtel, ${ }^{2} \mathrm{M}$ Nagel, ${ }^{1} \mathrm{M}$ Engel, ' $\mathrm{G}$ El Azzi, ${ }^{1} \mathrm{~A}$ Sharma, ${ }^{2} \mathrm{~J}$ Suggett. ${ }^{1}$ Boehringer Ingelheim Pharma GmbH and Co. KG, Biberach, Germany; ${ }^{2}$ Trudell Medical International, London, Canada

10.1136/thoraxjnl-2017-210983.228

Introduction Characterisation of any inhalation product requires a comprehensive assessment including in vitro, pharmacokinetic (PK), and clinical Results We assessed tiotropium Respimat ${ }^{\oplus}$ administered with the AeroChamber Plus ${ }^{\oplus}$ Flow-Vu ${ }^{\oplus}$ antistatic valved holding chamber (test $\mathrm{VHC}$ ) using in vitro, PK and clinical data in 1-5 year-olds with persistent asthmatic symptoms.

Methods We evaluated tiotropium delivered into a cascade impactor under fixed paediatric flow rates with and without holding times in the test VHC. Tidal breathing simulations and an anatomically correct ADAM-III Child Model were
B

\section{Oxygen Days}

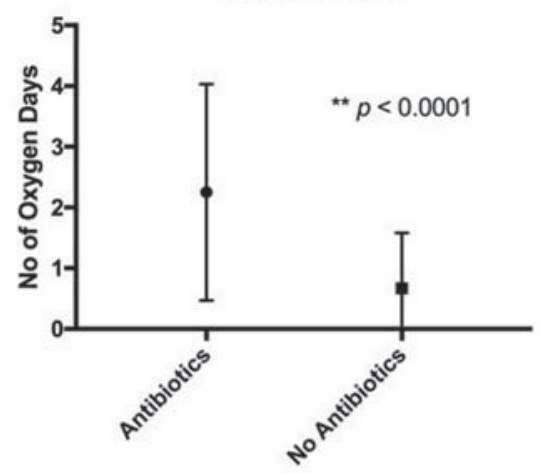

employed to assess the tiotropium mass likely to reach the lungs of preschool children when Respimat was administered with the test VHC. Clinical characterisation was based on a 12 week, randomised trial of once-daily tiotropium Respimat or placebo as add-on to background therapy in 1-5 year-olds with persistent asthmatic symptoms (NCT01634113). PK data on systemic exposure to tiotropium Respimat ${ }^{\oplus}$ administered with test VHC in preschool children were compared with pooled data from older patients with symptomatic persistent asthma not using VHCs (NCT01383499/NCT01122680/ NCT01233284/NCT01152450/NCT01696071/NCT00772538/ NCT00776984/NCT01172808/NCT01172821).

Results In vitro emitted mass decreased with lower flow conditions, indicating age-dependent dose reduction. In terms of dose per $\mathrm{kg} /$ body weight, delivered dosing at flow rates corresponding to preschool children was comparable to that at flow rates corresponding to older children (Table). Transmission and holding properties of tiotropium Respimat administered by test VHC were fully sufficient for aerosol delivery of patients. Standardised tidal inhalation resulted in emitted mass from the test VHC of approximately one-third of labelled dose, independent of coordination and face mask use, indicating predictable tiotropium administration by Respimat when used with test VHC. ADAM-III model data correlated well with standardised tidal breathing Results in terms of total mass delivered and mass delivered to filter (available to lungs). In separate clinical trials, tiotropium exposure in 1-5 year-old patients using the test VHC, adjusted by height or body surface, was comparable with that observed in older patients not using VHCs, with no overexposure. Safety of tiotropium Respimat in $1-5$ year-olds was comparable to placebo.

Conclusion This study supports administration of tiotropium Respimat ${ }^{\oplus}$ with the AeroChamber Plus ${ }^{\oplus}$ Flow-Vu ${ }^{\oplus}$ VHC in 15 year-old children with persistent asthmatic symptoms. 